\title{
Desenvolvimento inicial de maracujazeiros (Passiflora edulis f. flavicarpa, P. edulis f. edulis e P. alata) enxertados sobre Passiflora cincinnata
}

\author{
Initial development of passion fruit trees \\ (Passiflora edulis f. flavicarpa, P. edulis f. edulis and P. alata) \\ grafted onto Passiflora cincinnata
}

\author{
Valdir Zucareli ${ }^{*}$; Elizabeth Orika Ono ${ }^{2}$; \\ Carmen Sílvia Fernandes Boaro ${ }^{3}$; Wilian Polaco Brambilla ${ }^{4}$
}

\section{Resumo}

O presente trabalho teve como objetivo avaliar o desenvolvimento inicial e os teores foliares de minerais em plantas de maracujazeiros (Passiflora edulis f. flavicarpa Deg., P. edulis f. edulis Sims. e P. alata Dryander) enxertadas sobre Passiflora cincinnata. Para a obtenção das mudas, as sementes foram semeadas em sacolas plásticas $(500 \mathrm{~mL})$ e quando as plântulas atingiram o estádio de duas folhas expandidas foi realizada a enxertia hipocotiledonar. Quinze dias após a enxertia foi realizado transplantio para vasos de 10 litros preenchidos com terra previamente corrigida e adubada, sendo utilizadas duas plantas por vaso e cada um correspondendo a uma parcela. Para cada espécie comercial estudada como enxerto foi utilizado delineamento experimental inteiramente casualizado em esquema fatorial $3 \times 5$ (tipo de planta $\mathrm{x}$ época de coleta) com quatro repetições de duas plantas por parcela e cinco coletas destrutivas. Como tipo de planta foi considerado $P$. cincinnata não enxertada, maracujá comercial não enxertado e maracujá comercial enxertado sobre $P$. cincinnata. A primeira coleta foi realizada 15 dias após o transplantio e as demais em intervalos de 14 dias $(60,74,88,102$ e 116 DAS). Em cada coleta foi contado o número de folhas por planta e realizadas medidas de área foliar, comprimento de caule, massa da matéria seca total, caule, raiz e folhas. Na última coleta foi realizada a análise da composição mineral das plantas (macro e micronutrientes). De forma geral, foi observado que a enxertia sobre a espécie $P$. cincinnata não interferiu de maneira prejudicial no desenvolvimento inicial e nos teores de minerais das plantas de maracujazeiros comerciais e que essa interferência variou conforme a copa utilizada.

Palavras-chave: Enxertia, maracujá, propagação

\begin{abstract}
The present work aimed to evaluate the initial growth and leaf mineral levels in passion fruit trees (Passiflora edulis f. flavicarpa Deg., P. edulis f. edulis Sims. and P. alata Dryander) grafted onto Passiflora cincinnata. To obtain seedlings, seeds were sown in plastic bags $(500 \mathrm{~mL})$ and hypocotyl
\end{abstract}

\footnotetext{
${ }^{1}$ Prof. Adjunto, Dept $^{\circ}$ de Ciências Agronômicas, Universidade Estadual de Maringá, UEM, Campus Regional de Umuarama, Umuarama, PR. E-mail: valdirzucareli@yahoo.com.br

2 Prof. Adjunto/Livre-Docente, Dept ${ }^{\circ}$ de Botânica, Instituto de Biociências de Botucatu, IBB, Universidade Estadual Paulista Júlio de Mesquita Filho, UNESP, Botucatu, SP. E-mail: eoono@ibb.unesp.br

${ }^{3}$ Prof $^{a}$ Adjunto, Dept ${ }^{\circ}$ de Botânica, Instituto de Biociências de Botucatu, IBB, UNESP, Botucatu, SP. E-mail: csfboaro@ibb.unesp. br

${ }^{4}$ Discente de Mestrado, Programa de pós-graduação em Botânica, Instituto de Biociências de Botucatu, IBB, UNESP, Botucatu, SP. E-mail: wilian_pb@hotmail.com

* Autor para correspondência
} 
grafting was performed when seedlings reached the stage of two fully expanded leaves. Fifteen days after grafting, plants were transplanted to $10 \mathrm{~L}$ pots filled with previously limed and fertilized soil. Each pot contained two plants and corresponded to one plot. For each commercial species studied as rootstock, experimental design was completely randomized, in 3x5 (plant type $\mathrm{x}$ time of harvest) factorial arrangement, with four replicates of two plants per plot and five destructive harvests. Plant types were ungrafted $P$. cincinnata, ungrafted commercial passion fruit tree and commercial passion fruit tree grafted onto $P$. cincinnata. The first harvest was performed at 15 days after transplanting and the remaining ones at 14-day intervals $(60,74,88,102$ and 116 DAS). At each harvest, the number of leaves per plant was counted, and leaf area, stem length, and stem, root, leaf and total dry matter were estimated. At the last harvest, the mineral composition (macro and micronutrients) of plants was analyzed. In general, it was observed that grafting onto $P$. cincinnata did not interfere negatively with the initial development and mineral levels of commercial passion fruit trees, and this interference varied according to the used canopy.

Key words: Grafting, passion fruit, propagation

\section{Introdução}

Com a expansão dos pomares de maracujá, nos últimos 20 anos, houve aumento na demanda por informações técnicas e um dos aspectos comumente abordados é a obtenção de mudas de boa qualidade (MELETTI et al., 2002).

Neste contexto, a enxertia sobre espécies resistentes apresenta-se como prática recomendada por diversos autores (PACE, 1984; RUGGIERO, 2000; MELETTI; BRUCKNER, 2001), pois prolonga a vida útil das plantas, preserva a qualidade do material genético e, ainda, pode perenizar a cultura (LIMA, 2004).

Assim, para a seleção da espécie de porta enxerto é necessário que esta apresente facilidade de propagação, principalmente nos aspectos relacionados a germinação, crescimento e desenvolvimento das plantas no viveiro, uma vez que a viabilização comercial dessa prática necessita que as plantas tenham crescimento uniforme e sejam vigorosas, atingindo o ponto de enxertia num curto período de tempo. Contudo, a utilização de espécies de Passifloráceas como porta enxertos esbarra na falta de informações sobre o comportamento delas na fase de viveiro, bem como no sucesso, ou não, da combinação enxerto/porta enxerto (VASCONCELLOS et al., 2005).

No Brasil, ainda são escassas as informações sobre o comportamento de maracujazeiros enxertados sobre passifloras silvestres $\mathrm{e}$ as dificuldades no uso da enxertia consistem no fato dos porta enxertos oriundos de sementes da maioria das espécies silvestres, apresentarem o inconveniente de gerar plantas com caules muito finos e, portanto, incompatíveis com o diâmetro dos enxertos que são obtidos de plantas adultas (MELETTI; BRUCKNER, 2001).

Uma das espécies nativas com potencial para uso como porta enxerto é a Passiflora cincinnata Mast., que apresenta tolerância a doenças, como as causadas pela bactéria Xanthomonas campestris (MELETTI et al., 2002) e apresenta também, tolerância a nematóides (Meloidogyne $s p$ ) e ao déficit hídrico (ARAÚJO; SANTOS; LELO, 2004).

O desenvolvimento de plantas de maracujazeiro Azedo enxertadas sobre $P$. cincinnata foi estudado por Nogueira Filho et al. (2010) que observaram boa relação enxerto/porta enxerto entre as espécies e, embora as plantas não enxertadas de $P$. edulis f. flavicarpa tenham superado o seu desenvolvimento, os autores recomendam o uso do porta enxerto.

A interação entre enxerto e porta-enxerto é bastante complexa e ainda pouco entendida. Mas, dentre as possíveis influências do porta enxerto no desenvolvimento de plantas esta a interferência na absorção de água e condução hidráulica (BRANDÃO FILHO et al., 2003) e também, na na absorção e composição mineral das plantas (LIMA; MICHAN; SALIBE, 1980). 
A nutrição mineral influencia o desenvolvimento das plantas, pois tem efeito no crescimento, na morfogênese dos vegetais e na fotossíntese, uma vez que estes elementos minerais são componentes integrantes de enzimas e pigmentos ou, ainda, ativadores diretos do processo fotossintético (LARCHER, 2000; FAGERIA, 2001).

O porta enxerto pode, também, influenciar no crescimento da espécie por meio da maior ou menor síntese e transporte hormonal, visto que o sistema radicial desempenha papel importante na regulação hormonal do crescimento vegetal pela síntese de citocininas e ácido abscísico (ITAI; BIRNBAUM, 1991; TAIZ; ZEIGER, 2009).

De acordo com o exposto, o presente trabalho teve como objetivo avaliar o desenvolvimento inicial e os teores foliares de minerais em plantas de maracujazeiros (Passiflora edulis f. flavicarpa Deg., P. edulis f. edulis Sims. e P. alata Dryander) enxertadas sobre Passiflora cincinnata Mast.

\section{Material e Métodos}

O trabalho foi realizado em casa de vegetação do Departamento de Botânica, Instituto de Biociências, da Universidade Estadual Paulista (UNESP), Câmpus de Botucatu-SP.

Como porta enxerto foi utilizada a espécie Passiflora cincinnata e como enxerto foram utilizadas as espécies Passiflora edulis f. flavicarpa (maracujá Azedo), P. edulis f. edulis (maracujá Roxo ou roxinho do Kenia) e $P$. alata (maracujá Doce).

As sementes do porta enxerto, provenientes de diversas plantas cultivadas no Campo Experimental da Caatinga, foram obtidas junto ao Centro de Pesquisa Agropecuária do Trópico Semi-Árido (CPATSA) - Embrapa, Petrolina - PE.

As sementes de Passiflora edulis f. flavicarpa ('Gold Star'), P.edulis f. edulis e P. alata foram obtidas junto ao Departamento de Produção Vegetal (Horticultura) da Faculdade de Ciências
Agronômicas da UNESP, Campus de Botucatu-SP.

Para a obtenção das mudas, as sementes foram semeadas em sacolas plásticas $(500 \mathrm{~mL})$ e para facilitar a enxertia, devido às diferenças do diâmetro dos caules, as sementes do porta enxerto foram semeadas sete dias antes da espécie copa. Quando as plântulas atingiram o estádio de duas folhas expandidas (aproximadamente, 30 dias após a semeadura - DAS) foi realizada a enxertia.

Quinze dias após a enxertia (45 DAS) as plantas foram transplantadas para vasos de 10 litros preenchidos com terra previamente corrigida e adubada conforme análise química do solo, sendo utilizadas duas plantas por vaso e cada um correspondendo a uma parcela.

Para cada espécie comercial estudada como enxerto foi utilizado delineamento experimental inteiramente casualizado em esquema fatorial $3 \mathrm{x}$ 5 (tipo de planta x coleta) com quatro repetições de duas plantas por parcela e cinco coletas destrutivas, ou seja, cada espécie constituiu um experimento.

Como tipo de planta foi considerado $P$. cincinnata não enxertada, maracujazeiro comercial não enxertado e enxertado sobre $P$. cincinnata. A primeira coleta foi realizada 15 dias após o transplantio, ou seja, 60 DAS, e as demais, a intervalos de 14 dias (74, 88, 102 e 116 DAS).

Em cada coleta foi contado o número de folhas por planta e realizadas medidas de área foliar, comprimento de caule, massa da matéria seca total, caule, raiz e folhas.

A área foliar foi obtida por meio de integralizador de área, Area Meter modelo Li-3100 da Li-Cor e expressa em $\mathrm{cm}^{2}$ e as medidas do comprimento de caule foram obtidas com o auxílio de fita métrica graduada em milímetros e as médias expressas em $\mathrm{cm}$ sendo o comprimento considerado a medida do colo ao ápice da planta.

Para obtenção das massas de matéria seca, as raízes, caules e folhas das plantas foram separados, colocadas em sacos de papel identificados e 
colocadas para secar em estufa de circulação forçada de ar a $60^{\circ} \mathrm{C} \pm 3$ até massa constante. Então, foram pesadas em balança semi-analítica e os resultados expressos em gramas por planta.

Também foi realizada a análise da composição mineral das plantas (macro e micronutrientes). Para essas análises foram utilizadas a matéria seca foliar total de cada planta coletadas aos 116 DAS (última coleta) quando as folhas foram lavadas com água deionizada, acondicionadas em sacos de papel e secas em estufa com circulação forçada de ar à temperatura de $60^{\circ} \mathrm{C}$.

Após a secagem, o material foi triturado em moinho tipo Wiley com peneira de 20 mesh, armazenadas em sacos de papel e levadas até o Laboratório de Nutrição Mineral de Plantas do Departamento de Recursos Naturais/Ciências do Solo da Faculdade de Ciências Agronômicas (FCA), Universidade Estadual Paulista (UNESP), Campus de Botucatu-SP. As determinações dos teores de macro e micronutrientes presentes nas folhas foram realizadas de acordo com metodologia descrita por Malavolta, Vitti e Oliveira (1997).

Os dados de crescimento foram submetidos à análise de variância, sendo as médias para tipo de planta comparadas pelo teste Tukey a 5\% de probabilidade e as médias para coletas ao longo do tempo submetidas à análise de regressão, sendo as três espécies comerciais, usadas como enxertos, analisadas separadamente.

Os dados da composição mineral foram submetidos à análise de variância e as médias comparadas pelo teste Tukey a 5\% de probabilidade, sendo as espécies comerciais, usadas como enxerto, analisadas separadamente.

\section{Resultados e Discussão}

Observa-seque,independentedaespécieestudada, o maior número de folhas por planta foi obtido nas plantas de Passiflora cincinnata (porta enxerto) não enxertadas sendo este significativamente maior que nas espécies comerciais a partir da terceira coleta (maracujá Roxo e maracujá Doce) (Tabelas 2 e 3) e da quarta coleta (maracujá Azedo) (Tabela 1).

Nas espécies comerciais, o número de folhas por planta não foi alterado com a enxertia. Tais resultados demonstram que o sistema radicial do porta enxerto e da espécie comercial apresentaram comportamento semelhante para manutenção das folhas. Também, Beloygue et al. (1996) relatam que o número de folhas das plantas é geneticamente determinado e, dessa forma, é pouco influenciado pelos tratamentos. Resultados diferentes são mencionados por Nogueira Filho et al. (2010) que observaram diferença significativa no número de folhas entre plantas de $P$. edulis não enxertadas e enxertadas sobre $P$. cincinnata.

As médias para número de folhas foram ajustadas a funções lineares crescentes para todos os tipos de plantas. Quando comparadas plantas de maracujazeiros comerciais não enxertadas e enxertadas observa-se que as retas estão sobrepostas para os maracujazeiros Azedo e Roxo (P. edulis) e com tendência de distanciamento entre as retas nas últimas coletas para o maracujazeiro Doce (P. alata) (Figuras 1, 2 e 3). 
Tabela 1. Número de folhas, área foliar $\left(\mathrm{cm}^{2}\right)$, altura de plantas $(\mathrm{cm})$, massas da matéria seca de folhas $(\mathrm{g})$, caules (g), raízes (g) e total das plantas (g), obtidas aos 60, 74, 88, 102 e 116 dias após a semeadura (DAS) de plantas de maracujazeiro, Passiflora cincinnata, . edulis f. flavicarpa não enxertadas e $P$. edulis f. flavicarpa enxertadas sobre P. cincinnata.

\begin{tabular}{|c|c|c|c|c|c|c|c|}
\hline \multirow[t]{3}{*}{ Tratamentos } & \multicolumn{7}{|c|}{ Número de Folhas } \\
\hline & \multicolumn{7}{|c|}{ Tempo (DAS) } \\
\hline & 60 & 74 & 88 & 102 & 116 & Equação de regressão & $\mathbf{R}^{2}$ \\
\hline P. cincinnata & $9,5 \mathrm{a}$ & $11,7 \mathrm{a}$ & $15,0 \mathrm{a}$ & $21,5 \mathrm{a}$ & $23,2 \mathrm{a}$ & $y=0,2634 x+4,9125$ & 96 \\
\hline P. edulis f. flavicarpa & $7,7 \mathrm{a}$ & $10,5 \mathrm{a}$ & $13,5 \mathrm{a}$ & $16,0 \mathrm{~b}$ & $17,2 \mathrm{~b}$ & $y=0,1759 x+5,4875$ & 98 \\
\hline P. edulis f. flav. Enxertia & $6,7 \mathrm{a}$ & $11,0 \mathrm{a}$ & $12,7 \mathrm{a}$ & $15,5 \mathrm{~b}$ & $17,7 \mathrm{~b}$ & $y=0,1866 x+4,7625$ & 98 \\
\hline CV (\%) & \multicolumn{7}{|c|}{12} \\
\hline \multicolumn{8}{|c|}{ Área Foliar $\left(\mathrm{cm}^{2}\right)$} \\
\hline P. cincinnata & $113 \mathrm{a}$ & $178 \mathrm{~b}$ & $282 \mathrm{~b}$ & $595 \mathrm{~b}$ & $595 \mathrm{~b}$ & $y=9,6929 x-56,539$ & 86 \\
\hline P. edulis f. flavicarpa & $209 \mathrm{a}$ & $451 \mathrm{a}$ & $738 \mathrm{a}$ & $1022 \mathrm{a}$ & $1186 \mathrm{a}$ & $y=18,045 x-36,228$ & 99 \\
\hline P. edulis f. flav. Enxertia & $153 \mathrm{a}$ & 393 a & $635 \mathrm{a}$ & $891 \mathrm{a}$ & $1091 \mathrm{a}$ & $y=16,968 x-79,696$ & 99 \\
\hline CV $(\%)$ & \multicolumn{7}{|c|}{17} \\
\hline \multicolumn{8}{|c|}{ Comprimento de Caule (cm) } \\
\hline P. cincinnata & $22 \mathrm{a}$ & $42 \mathrm{a}$ & $72 \mathrm{a}$ & $134 \mathrm{a}$ & $145 \mathrm{a}$ & $y=2,4179 x-18,6$ & 95 \\
\hline P. edulis f. flavicarpa & $13 \mathrm{a}$ & $41 \mathrm{a}$ & $61 \mathrm{a}$ & $109 \mathrm{~b}$ & $137 \mathrm{a}$ & $y=2,258 x-22,575$ & 98 \\
\hline P. edulis f. flav. Enxertia & $13 \mathrm{a}$ & $30 \mathrm{a}$ & $42 \mathrm{a}$ & $111 \mathrm{ab}$ & $147 \mathrm{a}$ & $\mathrm{y}=2,5009 x-149,35$ & 95 \\
\hline CV (\%) & & & & & 19 & & \\
\hline \multicolumn{8}{|c|}{ Massa da Matéria Seca de Folhas (g) } \\
\hline P. cincinnata & 0,69 a & $1,47 \mathrm{~b}$ & $2,32 \mathrm{c}$ & $4,58 \mathrm{c}$ & $5,46 \mathrm{c}$ & $\mathrm{y}=0,0903 \mathrm{x}-0,883$ & 96 \\
\hline P. edulis f. flavicarpa & 0,97 a & $2,84 \mathrm{a}$ & $5,46 \mathrm{~b}$ & $8,63 \mathrm{a}$ & $10,10 \mathrm{a}$ & $y=0,1718 x-1,6126$ & 98 \\
\hline P. edulis f. flav. Enxertia & 0,78 a & $2,37 \mathrm{ab}$ & $3,97 \mathrm{a}$ & $7,05 \mathrm{~b}$ & $8,71 \mathrm{~b}$ & $y=0,1468 x-1,5851$ & 98 \\
\hline CV (\%) & & & & & 17 & & \\
\hline \multicolumn{8}{|c|}{ Massa da Matéria Seca de Caule (g) } \\
\hline P. cincinnata & $0,299 \mathrm{a}$ & $0,843 \mathrm{a}$ & $1,745 \mathrm{a}$ & $4,855 \mathrm{a}$ & $6,336 \mathrm{~b}$ & $y=0,0015 x 2-0,0101 x+0,0316$ & 96 \\
\hline P. edulis f. flavicarpa & $0,323 \mathrm{a}$ & $1,169 \mathrm{a}$ & $2,705 \mathrm{a}$ & $5,754 \mathrm{a}$ & $7,935 \mathrm{a}$ & $\mathrm{y}=0,0015 \mathrm{x} 2+0,0134 \mathrm{x}-0,2729$ & 99 \\
\hline P. edulis f. flav. Enxertia & $0,304 \mathrm{a}$ & $0,915 \mathrm{a}$ & $1,982 \mathrm{a}$ & $4,842 \mathrm{a}$ & $7,607 \mathrm{ab}$ & $\mathrm{y}=0,0022 \mathrm{x} 2-0,0544 \mathrm{x}+0,6216$ & 99 \\
\hline CV $(\%)$ & & & & & 12 & & \\
\hline \multicolumn{8}{|c|}{ Massa da Matéria Seca de Raiz (g) } \\
\hline P. cincinnata & $0,812 \mathrm{a}$ & $1,128 \mathrm{a}$ & $1,494 \mathrm{a}$ & $3,486 \mathrm{a}$ & $4,624 \mathrm{a}$ & $y=0,089 x-1,1816$ & 90 \\
\hline P. edulis f. flavicarpa & $0,875 \mathrm{a}$ & $1,291 \mathrm{a}$ & $2,339 \mathrm{a}$ & $3,264 \mathrm{a}$ & $4,365 \mathrm{a}$ & $y=0,064 x-0,2588$ & 98 \\
\hline P. edulis f. flav. Enxertia & $0,409 \mathrm{a}$ & $0,836 \mathrm{~b}$ & $1,819 \mathrm{a}$ & $2,875 \mathrm{a}$ & $4,413 \mathrm{a}$ & $\mathrm{y}=0,0717 \mathrm{x}-0,9424$ & 96 \\
\hline CV (\%) & & & & & 25 & & \\
\hline \multicolumn{8}{|c|}{ Massa da Matéria Seca de Planta (g) } \\
\hline P. cincinnata & $1,812 \mathrm{a}$ & 3,442 a & $5,564 \mathrm{~b}$ & $12,92 \mathrm{~b}$ & $16,42 \mathrm{~b}$ & $y=0,0033 x 2+0,0018 x+0,908$ & 97 \\
\hline P. edulis f. flavicarpa & $2,174 \mathrm{a}$ & $5,304 \mathrm{a}$ & $10,504 \mathrm{a}$ & $17,65 \mathrm{a}$ & $22,40 \mathrm{a}$ & $y=0,3773 x-4,236$ & 98 \\
\hline P. edulis f. flav. Enxertia & $1,495 \mathrm{a}$ & $4,123 \mathrm{a}$ & $7,779 \mathrm{ab}$ & $14,77 \mathrm{ab}$ & $20,73 \mathrm{a}$ & $\mathrm{y}=0,0036 \mathrm{x} 2+0,0447 \mathrm{x}+0,0445$ & 99 \\
\hline CV $(\%)$ & & & & & 9 & & \\
\hline
\end{tabular}

* Médias seguidas de letras iguais, na coluna, não diferem entre si pelo teste Tukey a 5\% de probabilidade.

Fonte: Elaboração pelos autores. 
O maior número de folhas apresentado pelo $P$. cincinnata não enxertado não resultou em maior área foliar por planta (Tabelas 1, 2 e 3) sendo, de maneira geral, as menores médias de área foliar observadas nesta espécie. A menor área foliar pode estar relacionada com a tolerância à seca apresentada pela espécie, pois segundo Santos e Carlesso (1998), a área foliar determina a quantidade de água transpirada pela planta.
As maiores médias para a área foliar foram observadas nas espécies comerciais, independentemente da enxertia. A exceção ficou por conta do maracujá Roxo que apresentou diferença significativa na área foliar entre as plantas não enxertadas e enxertadas na última coleta, sendo menor nas plantas enxertadas (Tabela 2).

Figura 1. Ajuste de regressão para número de folhas (A), área foliar (B), altura de plantas (C), massa da matéria seca de folhas (D), caules (E), raiz (F) e de plantas (G) em função do tempo $(60,74,88,102$ e 116 dias após a semeadura - DAS) a partir de plantas de maracujazeiro Passiflora cincinnata, P. edulis f. flavicarpa não enxertadas e enxertadas sobre P. cincinnata.

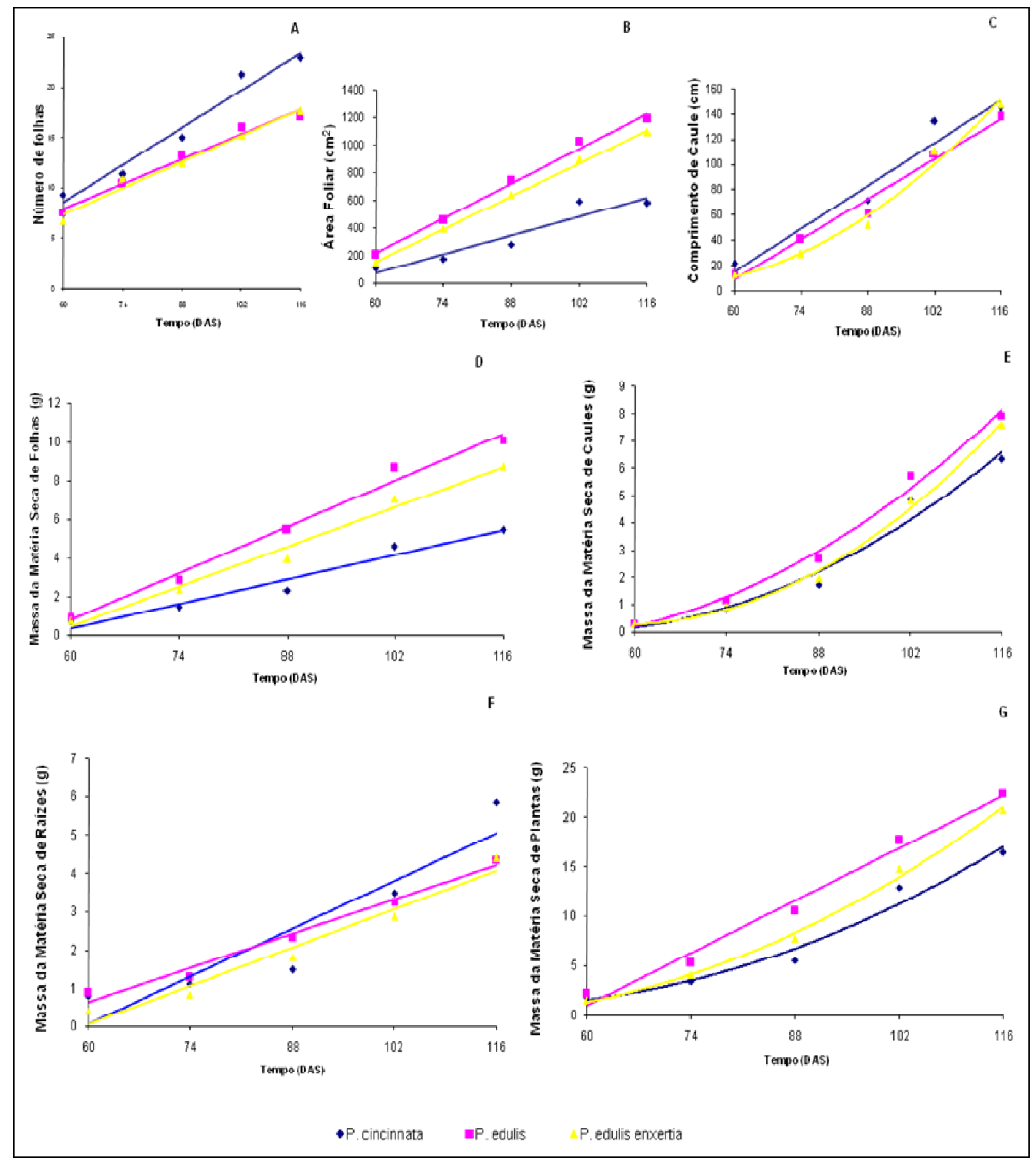

Fonte: Elaboração pelos autores. 
A área foliar, de maneira geral, ajustou-se a equações lineares crescentes em função das datas de coleta. Para o maracujá Roxo as curvas mostraram tendência de aumentar a distância entre as retas com o passar do tempo (Figura 2 - B), ou seja, a enxertia pode causar redução na área foliar nas plantas de maracujá Roxo, conforme diferença significativa observada na comparação de médias aos 116 DAS (Tabela 2). Cabe ressaltar que a diminuição da área foliar observada nas plantas enxertadas não implica, necessariamente, em menor produção, haja vista que pode diminuir o autosombreamento e, consequentemente, aumentar a fotossíntese líquida. Segundo Magalhães (1985) e Benincasa (2004), a taxa assimilatória líquida (TAL) depende dos fatores ambientais, principalmente da radiação solar. Devido ao auto-sombreamento a TAL diminui com o aumento do índice de área foliar e, consequentemente, com o crescimento da comunidade vegetal.

Figura 2. Ajuste de regressão para número de folhas (A), área foliar (B), altura de plantas (C), massa da matéria seca de folhas (D), caules (E), raiz (F) e de plantas (G) em função do tempo (60, 74, 88, 102 e 116 dias após a semeadura DAS) a partir de plantas de maracujazeiro Passiflora cincinnata, P. edulis f. edulis não enxertadas e enxertadas sobre P. cincinnata.

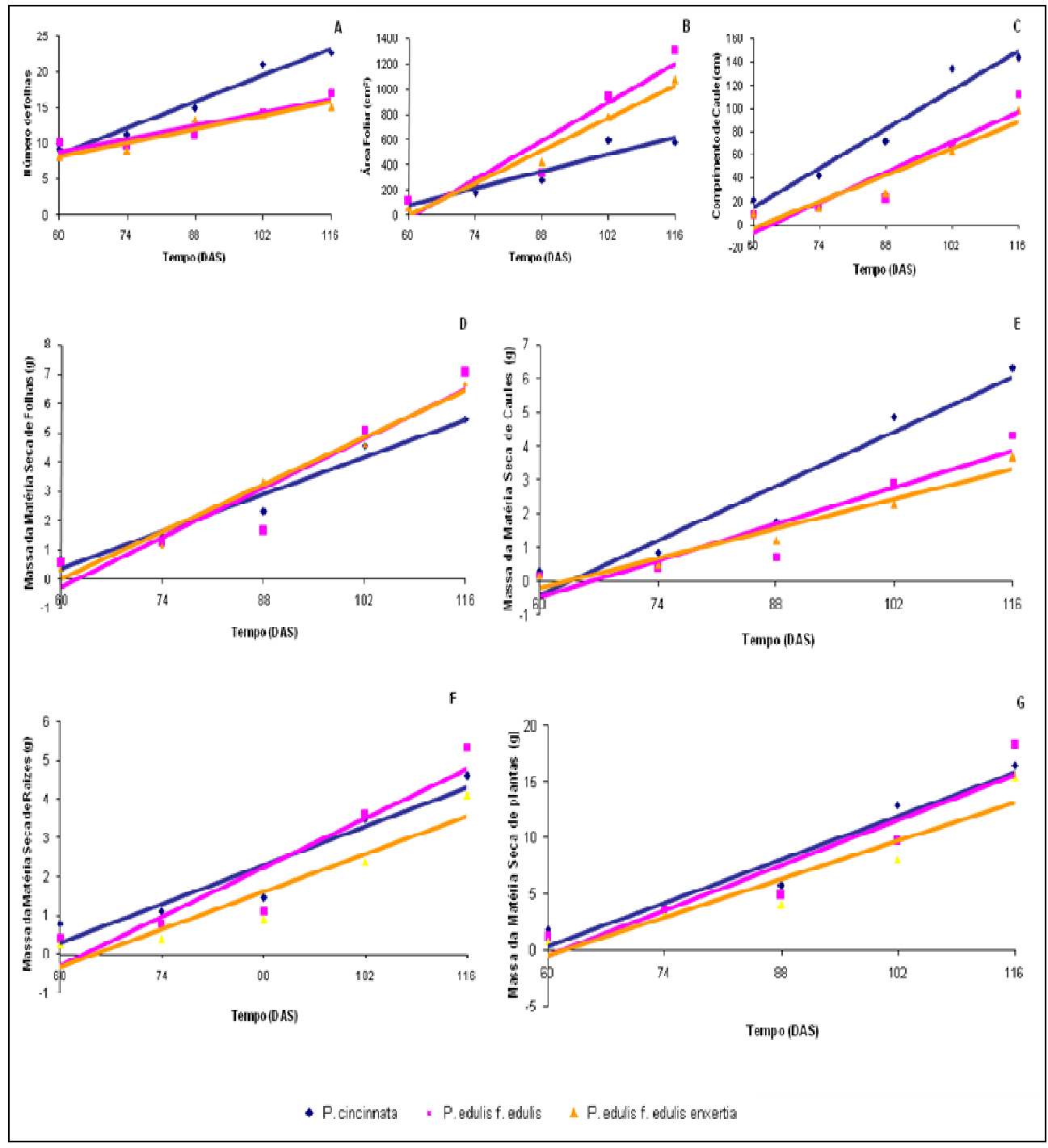

Fonte: Elaboração pelos autores. 
Para comprimento de caule não foi observada diferença entre os tipos de mudas para o maracujá Azedo (Tabela 1) sendo as médias ajustadas a equações lineares crescentes em função do tempo. Esses resultados são semelhantes aos obtidos por Nogueira Filho et al. (2010) que observaram velocidade constante de crescimento nas plantas de maracujazeiro Azedo enxertadas sobre $P$. cincinnata, não havendo diferença na altura de plantas para os dois tratamentos.
A enxertia hipocotiledonar utilizada nesse experimento pode ter contribuído para a não redução no tamanho das plantas enxertadas. Pois, segundo Santos, Ribeiro e Crespí (2004), em cerejeira (Prunus avium), a elevação da altura de enxertia pode diminuir o vigor das plantas levando ao efeito ananicante. Dessa forma, a utilização de outras técnicas de enxertia pode demonstrar efeitos diferenciados em relação aos obtidos nesse estudo.

Figura 3. Ajuste de regressão para número de folhas (A), área foliar (B), altura de plantas (C), massa da matéria seca de folhas (D), caules (E), raiz (F) e de plantas (G) em função do tempo $(60,74,88,102$ e 116 dias após a semeadura - DAS) a partir de plantas de maracujazeiro Passiflora cincinnata, $P$. alata não enxertadas e enxertadas sobre $P$. cincinnata.

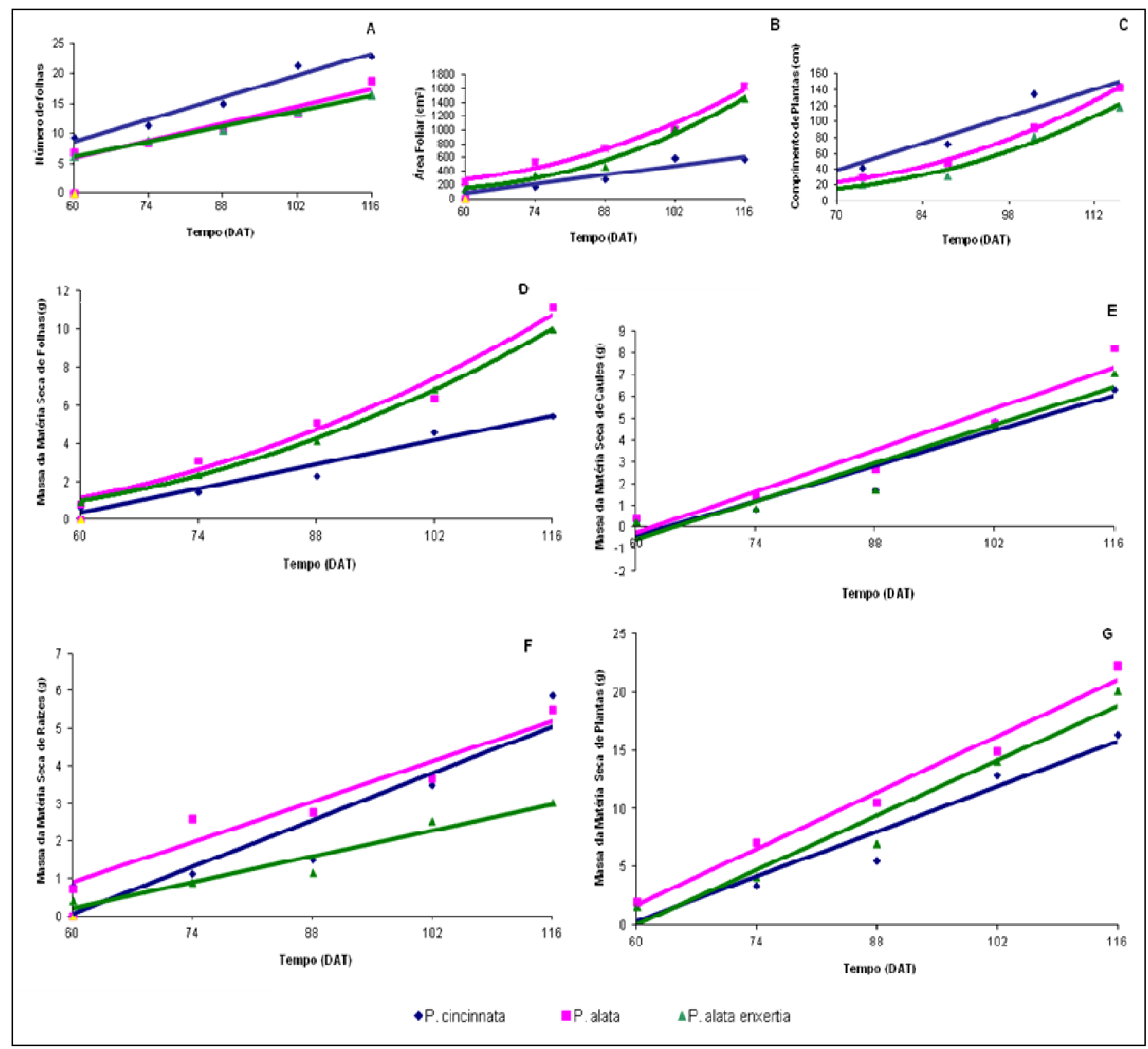

Fonte: Elaboração pelos autores. 
No experimento com maracujazeiro Roxo, as plantas de $P$. cincinnata não enxertadas apresentaram comprimento de caule significativamente maior e, entre as plantas de maracujá Roxo não enxertadas e enxertadas, não houve diferença significativa
(Tabela 2). No entanto, na Figura $2-\mathrm{C}$, o ajuste a equações lineares crescentes, mostra tendência de distanciamento entre as retas com o passar do tempo, com maior comprimento para as plantas não enxertadas.

Tabela 2. Número de folhas, área foliar $\left(\mathrm{cm}^{2}\right)$, altura de plantas $(\mathrm{cm})$, massas da matéria seca de folhas ( $\left.\mathrm{g}\right)$, caules $(\mathrm{g})$, raízes (g) e total das plantas (g), obtidas aos 60, 74, 88, 102 e 116 dias após a semeadura (DAS) de plantas de maracujazeiro, Passiflora cincinnata, P. edulis f. edulis não enxertadas e de P. edulis f. edulis enxertadas sobre P. cincinnata.

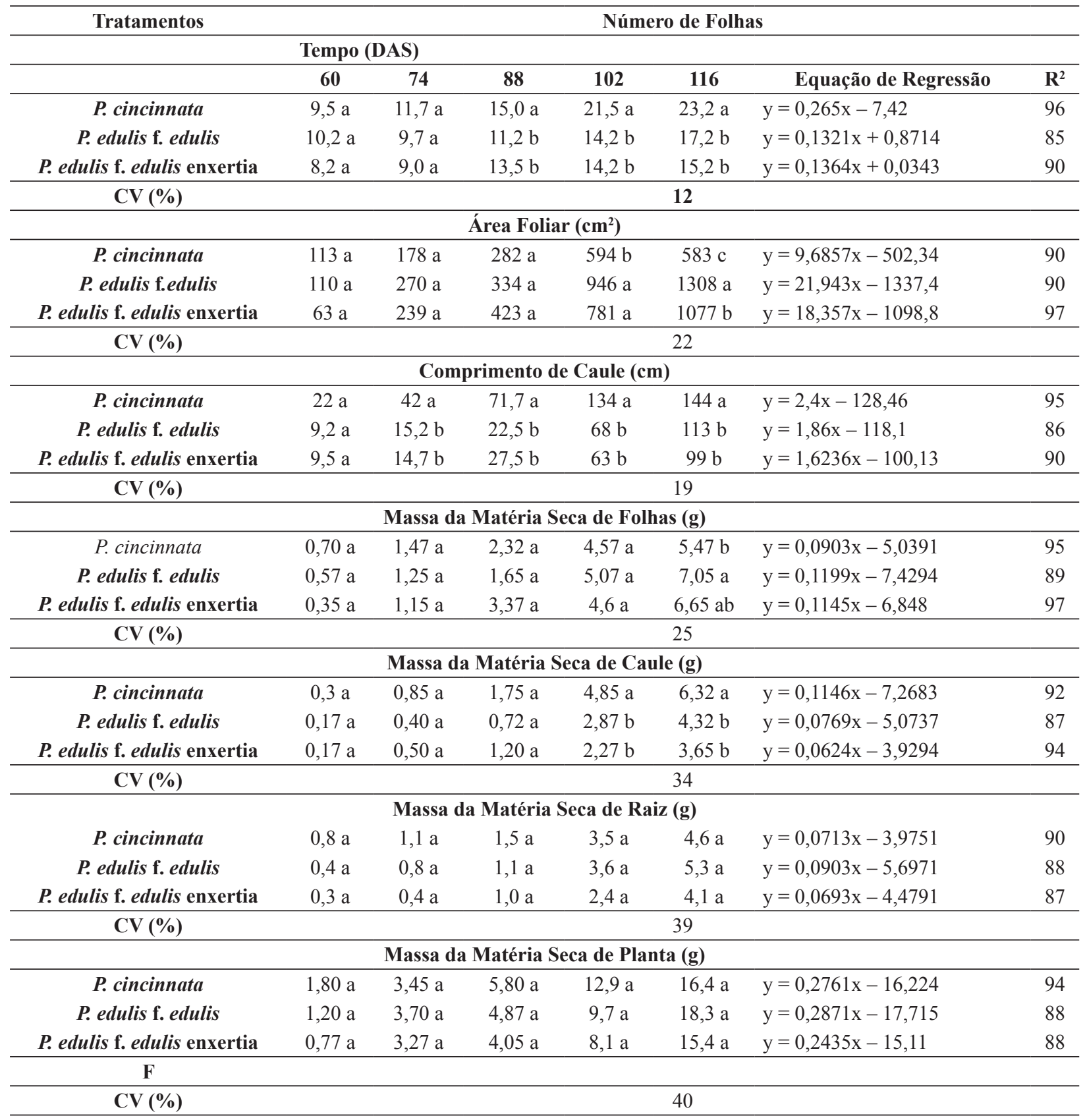

* Médias seguidas de letras iguais, na coluna, não diferem entre si pelo teste Tukey a 5\% de probabilidade.

Fonte: Elaboração pelos autores. 
As plantas de maracujá Doce apresentaram comportamento semelhante ao descrito para o maracujazeiro Roxo, sendo os caules menores nas plantas desta espécie quando comparadas ao de $P$, cincinnata não enxertado e não havendo diferença significativa entre as plantas não enxertadas e enxertadas (Tabela 3). A peculiaridade é o ajuste a equações de segundo grau que mostra tendência de recuperação do crescimento das plantas enxertadas assim como de $P$. alata sem enxertia (Figura 3 - C).

Tabela 3. Número de folhas, área foliar $\left(\mathrm{cm}^{2}\right)$, altura de plantas $(\mathrm{cm})$, massas da matéria seca de folhas $(\mathrm{g})$, caules $(\mathrm{g})$, raízes $(\mathrm{g})$ e total das plantas $(\mathrm{g})$, obtidas aos 60, 74, 88, 102 e 116 dias após a semeadura (DAS) de plantas de maracujazeiro, Passiflora cincinnata, $P$. alata não enxertadas e $P$. alata enxertadas sobre $P$. cincinnata.

\begin{tabular}{|c|c|c|c|c|c|c|c|}
\hline \multirow{3}{*}{ Tratamentos } & \multicolumn{7}{|c|}{ Número de Folhas } \\
\hline & \multicolumn{7}{|c|}{ Tempo (DAS) } \\
\hline & 60 & 74 & 88 & 102 & 116 & Equação Matemática & $\mathbf{R}^{2}$ \\
\hline P. cincinnata & $9,5 \mathrm{a}$ & $11,7 \mathrm{a}$ & $15,0 \mathrm{a}$ & $21,5 \mathrm{a}$ & $23,2 \mathrm{a}$ & $y=0,2634 x+4,9125$ & 96 \\
\hline P. alata & $7,0 \mathrm{a}$ & $8,7 \mathrm{a}$ & $11,0 \mathrm{~b}$ & $13,5 \mathrm{~b}$ & $19,0 \mathrm{~b}$ & $y=0,2045 x-6,3429$ & 94 \\
\hline P. alata enxertia & $6,5 \mathrm{a}$ & $8,7 \mathrm{a}$ & $10,7 \mathrm{~b}$ & $14,0 \mathrm{~b}$ & $17,0 \mathrm{~b}$ & $\mathrm{y}=0,1804 \mathrm{x}+3,625$ & 99 \\
\hline CV (\%) & \multicolumn{7}{|c|}{12} \\
\hline \multicolumn{8}{|c|}{ Área Foliar (cm²) } \\
\hline P. cincinnata & 113 a & $178 \mathrm{~b}$ & $282 \mathrm{~b}$ & $533 \mathrm{~b}$ & $595 \mathrm{c}$ & $y=9,6929 x-56,539$ & 86 \\
\hline P. alata & $230 \mathrm{a}$ & $534 \mathrm{a}$ & $735 \mathrm{a}$ & 1002 a & $1642 \mathrm{a}$ & $y=0,269 x 2+0,915 x+210,57$ & 98 \\
\hline P. alata enxertia & $138 \mathrm{a}$ & $352 \mathrm{ab}$ & $467 \mathrm{ab}$ & 1009 a & $1459 \mathrm{ab}$ & $y=0,3279 x 2-3,9676 x+145,04$ & 98 \\
\hline CV $(\%)$ & \multicolumn{7}{|c|}{22} \\
\hline \multicolumn{8}{|c|}{ Comprimento de Caule (cm) } \\
\hline P. cincinnata & $21 \mathrm{a}$ & $42 \mathrm{a}$ & $72 \mathrm{a}$ & $134 \mathrm{a}$ & $145 \mathrm{a}$ & $y=2,4179 x-18,6$ & 95 \\
\hline P. alata & $16 \mathrm{a}$ & $31 \mathrm{a}$ & $49 \mathrm{ab}$ & $93 \mathrm{~b}$ & $143 \mathrm{ab}$ & $y=0,0355 x 2-0,7371 x+20,588$ & 99 \\
\hline P. alata enxertia & $16 \mathrm{a}$ & $21 \mathrm{a}$ & $32 \mathrm{~b}$ & $83 \mathrm{c}$ & $119 \mathrm{~b}$ & $y=0,0333 x 2-0,8134 x+15,313$ & 98 \\
\hline CV $(\%)$ & \multicolumn{7}{|c|}{19} \\
\hline \multicolumn{8}{|c|}{ Massa da Matéria Seca de Folhas (g) } \\
\hline P. cincinnata & $0,69 \mathrm{a}$ & $1,47 \mathrm{a}$ & $2,32 \mathrm{~b}$ & $4,58 \mathrm{c}$ & $5,46 \mathrm{c}$ & $y=0,0903 x-0,883$ & 96 \\
\hline P. alata & $0,82 \mathrm{a}$ & 3,13 a & 5,09 a & $6,42 \mathrm{~b}$ & $11,18 \mathrm{a}$ & $y=0,0015 x 2+0,0413 x+0,2573$ & 97 \\
\hline P. alata enxertia & $0,82 \mathrm{a}$ & $2,36 \mathrm{ab}$ & $4,17 \mathrm{a}$ & $6,89 a b$ & $9,99 \mathrm{ab}$ & $\mathrm{y}=0,0016 \mathrm{x} 2+0,028 \mathrm{x}+0,2862$ & 99 \\
\hline CV $(\%)$ & \multicolumn{7}{|c|}{10} \\
\hline \multicolumn{8}{|c|}{ Massa da Matéria Seca de Caules (g) } \\
\hline P. cincinnata & $0,261 \mathrm{a}$ & 0,843 a & $1,745 \mathrm{a}$ & $4,855 \mathrm{a}$ & $6,336 \mathrm{~b}$ & $y=0,0015 x 2-0,0101 x+0,0316$ & 96 \\
\hline P. alata & $0,448 \mathrm{a}$ & $1,451 \mathrm{a}$ & $2,682 \mathrm{a}$ & $4,813 \mathrm{a}$ & $8,245 \mathrm{a}$ & $y=0,0021 x 2-0,0408 x+0,7198$ & 99 \\
\hline P. alata enxertia & $0,261 \mathrm{a}$ & $0,894 \mathrm{a}$ & $1723 \mathrm{a}$ & $4,714 \mathrm{a}$ & $7,099 \mathrm{ab}$ & $\mathrm{y}=0,0021 \mathrm{x} 2-0,0485 \mathrm{x}+0,5232$ & 99 \\
\hline CV $(\%)$ & \multicolumn{7}{|c|}{ ( } \\
\hline \multicolumn{8}{|c|}{ Massa da Matéria Seca de Raiz (g) } \\
\hline P. cincinnata & $0,812 \mathrm{a}$ & $1,128 \mathrm{ab}$ & $1,494 \mathrm{ab}$ & $3,486 \mathrm{a}$ & $4,624 \mathrm{ab}$ & $y=0,089 x-5,2763$ & 86 \\
\hline P. alata & 0,706 a & $2,573 \mathrm{a}$ & $2,765 \mathrm{a}$ & $3,661 \mathrm{a}$ & $5,503 \mathrm{a}$ & $y=0,0763 x-0,1628$ & 93 \\
\hline P. alata enxertia & $0,387 \mathrm{a}$ & $0,883 \mathrm{~b}$ & $1,138 \mathrm{~b}$ & $2,535 \mathrm{a}$ & $3,025 \mathrm{~b}$ & $\mathrm{y}=0,0495 \mathrm{x}-0,484$ & 94 \\
\hline \multicolumn{8}{|l|}{$\mathbf{F}$} \\
\hline CV $(\%)$ & & & & & 20 & & \\
\hline \multicolumn{8}{|c|}{ Massa da Matéria Seca de Plantas (g) } \\
\hline P. cincinnata & $1,812 \mathrm{a}$ & $3,442 \mathrm{~b}$ & $5,564 \mathrm{~b}$ & $12,92 \mathrm{~b}$ & $16,42 \mathrm{~b}$ & $y=0,2765 x-16,296$ & 93 \\
\hline P. alata & $1,976 \mathrm{a}$ & 7,163 a & $10,542 \mathrm{a}$ & $14,89 \mathrm{ab}$ & $22,32 \mathrm{a}$ & $y=0,3459 x-3,1486$ & 98 \\
\hline P. alata enxertia & $1,626 \mathrm{a}$ & $4,147 \mathrm{~b}$ & $7,033 \mathrm{~b}$ & $14,13 \mathrm{ab}$ & $20,12 \mathrm{ab}$ & $y=0,3356 x-20,122$ & 94 \\
\hline CV $(\%)$ & & & & & 9 & & \\
\hline
\end{tabular}

* Médias seguidas de letras iguais, na coluna, não diferem entre si pelo teste Tukey a 5\% de probabilidade.

Fonte: Elaboração pelos autores. 
A tendência de menor altura em plantas enxertadas é comum na fruticultura e é denominado de efeito ananicante. Algumas das causas desse efeito é a diminuição do diâmetro dos vasos xilemáticos (BAAS et al., 1984) e o surgimento de uma zona de descontinuidade no ponto de enxertia que aumenta a resistência ao transporte de água (BRANDÃO FILHO et al., 2003); menor capacidade de transporte de nutrientes (EBEL et al., 2000) e a menor síntese hormonal (SORCE et al., 2002). É necessário ressaltar que, no presente trabalho, foi realizado a enxertia hipocotiledonar e, dessa forma, a plantas apresentam a fase juvenil durante seu desenvolvimento, o que não ocorreria na enxertia com uso de tecido adulto.

O tipo de muda alterou a massa de matéria seca das folhas (Tabelas 1, 2 e 3) e a maior interferência ocorreu nas plantas de maracujazeiro Azedo (Tabela 1) sendo as maiores médias obtidas a partir de plantas de $P$. edulis não enxertadas e as menores médias obtidas nas plantas não enxertadas de $P$. cincinnata. Já as plantas enxertadas apresentaram médias intermediárias e no estudo de regressão (Figura 1-D) é possível observar que há tendência da massa da materia seca das folhas das plantas enxertadas permanecerem abaixo das demais, sendo que para os três tipos de mudas (porta enxerto, não enxertadas e enxertadas) foram obtidos ajustes a equações lineares crescentes. Tais resultados demonstram que a enxertia interfere no acúmulo de massa seca nas folhas e como não houve, para essa espécie, diferenças entre plantas enxertadas e não enxertadas no número de folhas e área foliar, acredita-se que a enxertia tenha interferido na produção e, ou translocação de fotoassimilados ou no consumo dos mesmos pelas folhas.

Diferente do maracujazeiro Azedo, nos maracujazeiros Roxo e Doce (Tabelas 2 e 3) as massas da matéria seca de folhas das plantas não enxertadas e enxertadas não diferiram entre si. Plantas enxertadas e não enxertadas apresentaram comportamento de acúmulo de massa ao longo do tempo semelhante sem tendência de diferirem (Figuras 2-D e 3-D).
Para o acúmulo de massa seca nos caules houve comportamento diferenciado para as três espécies comerciais estudadas. No maracujazeiro Azedo, apesar de maiores números absolutos nas plantas não enxertadas, essas não diferiram das plantas enxertadas (Tabela 1) e no estudo de regressão, os três tipos de mudas foram ajustados a equações de segundo grau (Figura 1 - E) com tendência de aproximação entre plantas não enxertadas e enxertadas que provavelmente, está relacionado à superação do estresse causado pela enxertia durante a fase inicial do experimento.

Dentre as três espécies estudadas, as plantas de maracujazeiro Roxo foram as únicas que apresentaram massa seca de caule menor que a massa seca de caule de $P$. cincinnata não enxertado diferindo significativamente a partir da quarta coleta e não havendo diferenças entre plantas enxertadas e não enxertadas da mesma espécie (Tabela 2), indicando que $P$. edulis f. edulis teve menor acumulo de matéria seca no caule, sendo ou não enxertado, sendo os dados para os tipos de mudas ajustados a retas lineares crescentes ao longo do tempo (Figura $2-\mathrm{E})$.

Para o maracujazeiro Doce, as plantas enxertadas apresentaram valores de massa seca de caule intermediários não diferindo dos demais tratamentos (Tabela 3). Porém, observou-se tendência de distanciamento entre as retas para as plantas de $P$. alata não enxertadas e enxertadas (Figura 3-E), o que demonstra que a enxertia pode ter maior efeito nessa variável em plantas adultas, originando plantas de menor porte ou menos produtivas. Segundo Basile et al. (2003) a menor massa seca de caule, em geral, acontece em copas enxertadas sobre porta enxertos ananicantes, que priorizam a distribuição da matéria seca para as raízes e folhas, enquanto as plantas enxertadas sobre porta enxertos mais vigorosos privilegiam também o caule.

$\mathrm{Na}$ massa da matéria seca de raiz (Tabelas 1,2 e 3) não houve diferença entre os tratamentos para os maracujazeiros Azedo e Roxo. Entretanto, a 
enxertia causou redução na massa seca de raízes do maracujazeiro Doce (Tabela 3). A menor massa seca de raiz e a constatação de tendência de menor altura de planta e menor massa seca de caules, indica que a espécie $P$. cincinnata pode não ser considerada um porta enxerto vigoroso, pois, o menor sistema radicial implicaria menor área explorada do solo.

Quanto a massa da matéria seca total de plantas observa-se que não houve interferência dos tipos de muda nessa variável (Tabelas 1, 2 e 3) para a qual, os maracujazeiros Azedo e Doce apresentaram massas superiores ao do $P$. cincinnata não enxertado e o maracujazeiro Roxo apresentou massas semelhantes às do $P$. cincinnata não enxertado, independentemente da enxertia.

Observa-se na Figura 1-G que, para o maracujazeiroAzedo (Passiflora edulis f. flavicarpa) a massa da matéria seca total das plantas enxertadas apresenta tendência de recuperação, aproximandose das plantas de $P$. edulis não enxertada nas últimas coletas. O inverso ocorre para o maracujazeiro Roxo, que demonstra tendência de distanciamento (Figura 2-G). No maracujazeiro Doce, as retas seguem paralelas.

Assim, pode-se dizer que a enxertia interfere de forma diferenciada no acúmulo de massa seca nas três espécies estudadas.

Os teores de nutrientes foliares estão apresentados nas Tabela 4 (macronutrientes) e Tabela 5 (micronutrientes). Apesar de relatos da influência positiva da enxertia sobre a absorção e composição mineral das plantas (LIMA; MICHAN; SALIBE, 1980) é possível observar que a influência do porta enxerto variou de acordo com a espécie e com o mineral estudado. Essa variação, principalmente entre as espécies, se deve às diferenças genéticas entre as mesmas, pois segundo Gabelman e Gerloff (1983) há controle genético nos processos de absorção, transporte e redistribuição de nutrientes nas plantas.

Para o maracujazeiro Azedo o porta enxerto não interferiu nos teores dos macronutrientes $\mathrm{N}$ e $\mathrm{S}$ (Tabela 4) e dos micronutrientes B, Fe e Zn (Tabela 5). Porém, as plantas enxertadas apresentaram maiores teores de $\mathrm{P}, \mathrm{K}, \mathrm{Ca}, \mathrm{Mg}$ e $\mathrm{Cu}$ e menor teor de Mn quando comparadas às plantas de $P$. edulis $\mathrm{f}$. falvicarpa não enxertadas.

No maracujazeiro Roxo o porta enxerto não interferiu nos teores de macronutrientes, $\mathrm{N}$ e $\mathrm{P}$ (Tabela 4) e de micronutrientes, $\mathrm{Cu}$ e Mn (Tabela 5). Para todos os demais íons quantificados, as plantas enxertadas apresentaram valores significativamente menores quando comparadas às plantas não enxertadas da mesma espécie.

No maracujazeiro Doce apenas o $\mathrm{Mg}$ (Tabela 4) e $\mathrm{Cu}$ (Tabela 5) não diferiram entre plantas enxertadas e não enxertadas. Os teores dos macrocronutrientes, $\mathrm{N}, \mathrm{P}$ e K e dos micronutrientes, Fe, Mn e Zn, foram maiores nas plantas enxertadas. Já os teores de $\mathrm{Ca}$, $\mathrm{S}$ e $\mathrm{B}$ foram menores nas plantas enxertadas quando comparadas às plantas não enxertadas. 
Tabela 4. Teores foliares de macronutrientes obtidos aos 116 dias após a semeadura a partir de plantas de maracujazeiro, Passiflora cincinnata, maracujazeiros comerciais não enxertados e enxertados sobre P. cincinnata.

\begin{tabular}{|c|c|c|c|c|c|c|}
\hline \multirow{3}{*}{ Tratamentos } & \multicolumn{6}{|c|}{ Passiflora edulis f. flavicarpa } \\
\hline & $\mathbf{N}$ & $\mathbf{P}$ & $\mathbf{K}$ & Ca & $\mathbf{M g}$ & $\mathbf{S}$ \\
\hline & \multicolumn{6}{|c|}{$\left(\mathrm{g} \mathrm{kg}^{-1)}\right.$} \\
\hline$P$. cincinnata & $35 \mathrm{a}$ & $1,2 \mathrm{a}$ & $17,7 \mathrm{ab}$ & $16,5 \mathrm{a}$ & $3,0 \mathrm{~b}$ & $2,1 \mathrm{~b}$ \\
\hline P. edulis f. flavicarpa & $30 \mathrm{~b}$ & $1,0 \mathrm{~b}$ & $16,5 \mathrm{~b}$ & $10,7 \mathrm{c}$ & $2,2 \mathrm{c}$ & $2,4 \mathrm{a}$ \\
\hline P. edulis f. flavicarpa Enxertia & $30 \mathrm{~b}$ & $1,3 \mathrm{a}$ & $18,7 \mathrm{a}$ & $13,7 \mathrm{~b}$ & $3,4 \mathrm{a}$ & $2,3 \mathrm{a}$ \\
\hline C.V. $(\%)$ & 6 & 10 & 7 & 9 & 6 & 7 \\
\hline \multicolumn{7}{|c|}{ Passiflora edulis f. edulis } \\
\hline P. cincinnata & $35 \mathrm{a}$ & $1,0 \mathrm{~b}$ & $17,7 \mathrm{~b}$ & $16,5 \mathrm{~b}$ & $3,0 \mathrm{c}$ & $2,0 \mathrm{~b}$ \\
\hline P. edulis f. edulis & $34 \mathrm{a}$ & $2,6 \mathrm{a}$ & $20,0 \mathrm{a}$ & $19,5 \mathrm{a}$ & $10,1 \mathrm{a}$ & $4,6 \mathrm{a}$ \\
\hline P. edulis f. edulis Enxertia & $33 \mathrm{a}$ & $3,0 \mathrm{a}$ & $18,3 \mathrm{~b}$ & $14,8 \mathrm{~b}$ & $7,7 \mathrm{~b}$ & $2,6 \mathrm{~b}$ \\
\hline C.V. $(\%)$ & 4 & 19 & 6 & 11 & 14 & 16 \\
\hline \multicolumn{7}{|c|}{ Passiflora alata } \\
\hline P. cincinnata & $35 \mathrm{a}$ & $1,2 \mathrm{~b}$ & $17,7 \mathrm{a}$ & $16,5 \mathrm{a}$ & $3,0 \mathrm{a}$ & $2,1 \mathrm{~b}$ \\
\hline P. alata & $27 \mathrm{c}$ & $1,1 \mathrm{~b}$ & $12,7 \mathrm{c}$ & $13,7 \mathrm{~b}$ & $3,1 \mathrm{a}$ & $2,4 \mathrm{a}$ \\
\hline P. alata Enxertia & $30 \mathrm{~b}$ & $1,5 \mathrm{a}$ & $15,0 \mathrm{~b}$ & $11,2 \mathrm{c}$ & $2,8 \mathrm{a}$ & $2,2 \mathrm{~b}$ \\
\hline C.V. (\%) & 5 & 5 & 7 & 6 & 7 & 6 \\
\hline
\end{tabular}

* Médias seguidas de letras iguais, na coluna para cada espécie de maracujazeiro comercial, não diferem entre si pelo teste Tukey a $5 \%$ de probabilidade.

Fonte: Elaboração pelos autores.

Tabela 5. Teores foliares de micronutrientes obtidos aos 116 dias após a semeadura a partir de plantas de maracujazeiro, Passiflora cincinnata, maracujazeiros comerciais não enxertados e de maracujazeiros comerciais enxertados sobre $P$. cincinnata.

\begin{tabular}{|c|c|c|c|c|c|}
\hline \multicolumn{6}{|c|}{ Passiflora edulis f. flavicarpa } \\
\hline \multirow{2}{*}{ Tratamentos } & B & $\mathbf{C u}$ & $\mathbf{F e}$ & Mn & Zn \\
\hline & \multicolumn{5}{|c|}{$\left(\mathrm{mg} \mathrm{kg}^{-1}\right)$} \\
\hline P. cincinnata & $93 \mathrm{a}$ & $6,0 \mathrm{a}$ & $209 \mathrm{a}$ & $50 \mathrm{~b}$ & $14 \mathrm{a}$ \\
\hline P. edulis f. flavicarpa & $83 \mathrm{~b}$ & $4,6 \mathrm{~b}$ & $198 \mathrm{a}$ & $65 \mathrm{a}$ & $16 \mathrm{a}$ \\
\hline P. edulis f. flavicarpa Enxertia & $82 \mathrm{~b}$ & $6,0 \mathrm{a}$ & $212 \mathrm{a}$ & $51 \mathrm{~b}$ & $17 \mathrm{a}$ \\
\hline C.V. $(\%)$ & 9 & 11 & 7 & 11 & 16 \\
\hline \multicolumn{6}{|c|}{ Passiflora edulis f. edulis } \\
\hline P. cincinnata & $93 \mathrm{~b}$ & $6,0 \mathrm{a}$ & $209 \mathrm{a}$ & $50 \mathrm{a}$ & $14,2 \mathrm{c}$ \\
\hline P. edulis f. edulis & $277 \mathrm{a}$ & $3,3 \mathrm{~b}$ & $112 \mathrm{~b}$ & $48 \mathrm{a}$ & $38,8 \mathrm{a}$ \\
\hline P. edulis f. edulis Enxertia & $117 \mathrm{~b}$ & $3,5 \mathrm{~b}$ & $100 \mathrm{c}$ & $40 \mathrm{a}$ & $23,7 b$ \\
\hline C.V. $(\%)$ & 23 & 15 & 6 & 17 & 14 \\
\hline \multicolumn{6}{|c|}{ Passiflora alata } \\
\hline P. cincinnata & $87 \mathrm{~b}$ & $5,75 \mathrm{a}$ & $209 \mathrm{~b}$ & $52 \mathrm{a}$ & $14 \mathrm{~b}$ \\
\hline P. alata & $135 \mathrm{a}$ & $6,00 \mathrm{a}$ & $242 \mathrm{~b}$ & $27 \mathrm{c}$ & $14 \mathrm{~b}$ \\
\hline P. alata Enxertia & $74 \mathrm{~b}$ & $5,25 \mathrm{a}$ & $343 \mathrm{a}$ & $44 \mathrm{~b}$ & $19 \mathrm{a}$ \\
\hline C.V. $(\%)$ & 11 & 14 & 20 & 13 & 7 \\
\hline
\end{tabular}

* Médias seguidas de letras iguais, na coluna para cada espécie de maracujazeiro comercial, não diferem entre si pelo teste Tukey a $5 \%$ de probabilidade.

Fonte: Elaboração pelos autores. 
Os valores de $\mathrm{N}$ obtidos neste trabalho (30-35 $\mathrm{g} \mathrm{kg}^{-1}$ ) estão abaixo do recomendado por Menzel, Haydon e Simpson (1991) que observaram melhor crescimento das plantas de maracujazeiro híbrido (Azedo x Roxo) quando estes apresentavam teores foliares de $\mathrm{N}$ em torno de 45 a $55 \mathrm{~g} \mathrm{~kg}^{-1}$.

Os valores obtidos também diferem, em sua maioria, dos relatados por Carvalho et al. (2002) em maracujazeiro Azedo cultivado com diferentes doses de nitrogênio que apresentaram teores foliares nas diferentes épocas do ano variando de 40,8 a 58,1 $\mathrm{g} \mathrm{kg}^{-1}$ de N, 2,58 a 3,85 $\mathrm{g} \mathrm{kg}^{-1}$ de P, 23,2 a $38 \mathrm{~g} \mathrm{~kg}^{-1}$ de $\mathrm{K}, 6,13$ a $14,4 \mathrm{~g} \mathrm{~kg}^{-1}$ de Ca, 2,23 a 4,28 $\mathrm{g} \mathrm{kg}^{-1}$ de $\mathrm{Mg}$ e 3,2 a 4,64 $\mathrm{g} \mathrm{kg}^{-1}$ de S, 77 a $246 \mathrm{mg} \mathrm{kg}^{-1}$ de Fe, 21,1 a 31,8 $\mathrm{mg} \mathrm{kg}^{-1}$ de Zn, 44,4 a 94,5 $\mathrm{mg} \mathrm{kg}^{-1}$ de Mn, 34,1 a 48,9 mg kg-1 de B e 4,41 a 8,47 mg kg-1 de $\mathrm{Cu}$.

No presente trabalho, de maneira geral, com exceção do $\mathrm{Ca}, \mathrm{Mg}$, Fe e $\mathrm{Mn}$, as médias obtidas foram menores que as mencionadas pelos autores supra citados. É preciso ressaltar que, além da espécie, a idade das plantas e condições de cultivo foram diferentes. No entanto, não foram encontrados na literatura estudos com espécies da família Passifloraceae que contemplem o efeito da enxertia nos teores foliares de minerais e, dessa forma, a comparação dos resultados do presente trabalho fica prejudicada, o que não impede que tais resultados auxiliem a discussão de novos estudos relacionados ao tema.

Os resultados demonstraram que, de forma geral, a enxertia sobre a espécie $P$. cincinnata não interferiu de maneira prejudicial no desenvolvimento inicial e nos teores de minerais das plantas de maracujazeiros comerciais e que essa interferência variou conforme a enxerto utilizado.

\section{Referências}

ARAÚJO, F. P.; SANTOS, C. A. F.; LELO, F. M. Propagação vegetativa do maracujá do mato: espécies resistentes à seca, de potencial econômico para agricultura de sequeiro. Petrolina: Embrapa Semi-Árido, 2004. (Instruções Técnicas da Embrapa Semi-Árido, 61).
BAAS, P.; CHENGLEE, L.; XINYING, Z.; KEMING, C.; YUEFEN, D. Some effects of dwarf growth on Wood structure. International Association of Wood Anatomistis Bulletin, Leiden, v. 45, n. 1, p. 63-74, 1984.

BASILE, B.; MARSAL, J.; SOLARI, I.; TYREE, M. T.; BRYLA, D. R.; DEJONG, T. M. Hydraulic conductance ofpeach trees grafted on rootstocks with differing sizecontrolling potentials. Journal of Horticultural Science and Biotechnology, Ashford, v. 78, n. 6, p. 768-774, 2003.

BELOYGUE, C.; WERY, J.; COWAN, A. A.; TARDIEU, F. Contribution of leaf expansion, rates of leaf appearance, and stalon branching to growth of plants leaf area under water deficit in write clover. Crop Science, Madison, v. 36, n. 5, p. 1240-1246, 1996.

BENINCASA, M. M. P. Análise de crescimento de plantas: noções básicas. Jaboticabal: FUNEP, 2004. 42 p.

BRANDÃO FILHO, J. U. T.; GOTO, R.; GUIMARÃES, V. F.; HABERMANN, G.; RODRIGUES, J. D.; CALLEGARI, O. Influência da enxertia nas trocas gasosas de dois híbridos de berinjela cultivados em ambiente protegido. Horticultura Brasileira, Brasília, v. 21, n. 3, p. 474-477, 2003.

CARVALHO, A. J. C.; MONNERAT, P. H.; MARTINS, D. P.; BERNARDO, S.; SILVA, J. A. Teores foliares de nutrientes no maracujazeiro amarelo em função de adubação nitrogenada, irrigação e epócas de amostragem. Scientia Agricola, Piracicaba, v. 59, n. 1, p. 121-127, 2002.

EBEL, R. C.; CAYOR, A. W.; PITTS, J. A.; WILKINS, B. S. Mineral nutrition during establishment of Golden Delicious 'Smoothee' apples on dwarfing rootstocks and interstems. Journal of Plant Nutrition, Philadelphia, v. 23, n. 8, p. 1179-1192, 2000.

FAGERIA, V. D. Nutrient interactions in crop plants. Journal of Plant Nutrition, Monticello, v. 24, n. 8, p. 1269-1290, 2001.

GABELMAN, W. H.; GERLOFF, G. C. The search for and interpretation of genetic controls that enhance plant growth under deficiency levels of a macronutrient. Plant Soil, The Hague, v. 72, n. 1, p. 335-350, 1983.

ITAI, C.; BIRNBAUM, H. Synthesis of plant regulators by roots. In: WAISEL, Y.; ESHEL, A.; KAFKATI, U. Plant roots. New York: Basel, 1991. p. 163-178.

LARCHER, W. Ecofisiologia vegetal. São Carlos: Rima, 2000. 529 p.

LIMA, A. A. Aspectos fitotécnicos: desafios da pesquisa. In: FALEIRO, F. G.; JUNQUEIRO, N. T. V.; BRAGA, M. F. (Ed.). Maracujá: germoplasma e melhoramento genético. Plananltina: Embrapa Cerrados, 2004. p. 295313. 
LIMA, L. A.; MICHAN, M. M.; SALIBE, A. A. Concentração de boro e enxofre em folhas de laranjeiras doces, determinados por diferentes porta-enxertos e enxertos. Revista Brasileira de Fruticultura, Cruz das Almas, v. 2, n. 2, p. 54-61, 1980.

MAGALHÃES, A. C. N. Análise quantitativa do crescimento. In: FERRI, M. G. Fisiologia vegetal. São Paulo: EPU, 1985. v. 1, p. 363-50.

MAlaVOlTA, E.; VITTI, G. C.; OliVEIRA, S. A. Avaliação do estado nutricional das plantas: principios e aplicações. 2. ed. Piracicaba: Potafos, 1997. 319 p.

MELETTI, L. M. M.; BRÜCKNER, C. H. Melhoramento genético. In: BRÜCKNER, C. H.; PICANÇO, M. C. Maracujá: tecnologia de produção, pós-colheita, agroindústria e mercado. Porto Alegre: Cinco Continentes, 2001. p. 345-385.

MELETTI, L. M. M.; FURLANI, P. R.; ALVAREZ, V.; SOARES-SCOTT, M. D.; BERNACCI, L. C.; AZEVEDO-FILHO, J. A. Novas tecnologias melhoram a produção de mudas de maracujá. O Agronômico, Campinas, v. 54, n. 1, p. 30-33, 2002.

MENZEL, C. M.; HAYDON, G. E.; SIMPSON, D. R. Effect of nitrogen on growth and flowering of passionfruit (Passiflora edulis f. edulis x P. edulis f. flavicarpa) in sand culture. Journal of Horticultural Science, Ashford, v. 66, n. 6, p. 689-702, 1991.

NOGUEIRA FILHO, G. C.; RONCATTO, G.; RUGGIERO, C.; OLIVEIRA, J. C.; MALHEIROS, E. B. Desenvolvimento de plantas de maracujazeiro-amarelo produzidas por enxertia hipocotiledonar em cinco portaenxertos de passifloras silvestres. Revista Brasileira de Fruticultura, Cruz das Almas, v. 32, n. 2, p. 535-543, 2010.
PACE, C. A. M. Comparação de quatro métodos de enxertia para o maracujazeiro amarelo Passiflora edulis Sims f. flavicarpa deg. In: CONGRESSO BRASILEIRO DE FRUTICULTURA, 7., 1983, Florianópolis. Anais... Santa Catarina: SBF, 1984. p. 983-988.

RUGGIERO, C. Situação da cultura do maracujazeiro no Brasil. Informe Agropecuário, Belo Horizanote, v. 21, n. 206, p. 5-9, 2000.

SANTOS, A.; RIBEIRO, R. E.; CRESPÍ, A. L. Sweet cherry (Prunus avium) growth is mostly affected by rootstock and much less by budding height. New Zealand Journal of Crop and Horticultural Science, Wellington, v. 32, n. 3, p. 309-318, 2004.

SANTOS, R. F.; CALESSO, R. Déficit hídrico e os processos morfológicos e fisiológicos das plantas. Revista Brasileira de Engenharia Agrícola e Ambiental, Campina Grande, v. 2, n. 3, p. 287-294, 1998.

SORCE, C.; MASSAI, R.; PICCIARELLI, P.; LORENZI, $\mathrm{R}$. Hormonal relationships in xylem sap of grafted and ungrafted Prunus rootstocks. Scientia Horticulturae, Amsterdam, v. 93, n. 3, p. 333-342, 2002.

TAIZ, L.; ZEIGER, E. Fisiologia vegetal. 4. ed. Porto Alegre: Artimed, 2009. 819 p.

VASCONCELlOS, M. A. S.; SILVA, A. C.; SILVA, A. C.; REIS, F. O. Ecofisiologia do maracujazeiro e implicações na exploração diversificada. In: FALEIRO, F. G.; JUNQUEIRO, N. T. V.; BRAGA, M. F. (Ed.). Maracujá: germoplasma e melhoramento genético. Planaltina: Embrapa Cerrados, 2005. p. 295-313. 
